\title{
Comments
}

A case of bilateral abducens paralysis is reported, which was treated by transplantation of the outer halves of the superior and inferior recti to the insertion of the paralysed external rectus. This latter muscle was much thicker than normal, and showed in the left eye an abnormal anatomical position.

I thought that a possible explanation for the abnormal thickness of the external rectus (one would have expected a thin, frail muscle in a congenital paralysis of the 6 th-nerve), might be the innervation of the external rectus by the 3 rd nerve instead, of the 6 th. (The internal and external recti always contracting at the same time). But Miss Ida Mann, of Oxford, informed me that this is embryalogically impossible, because the 6 th nerve is the motor nerve of the 3 rd head cavity, and the 3 rd nerve of the 1 st head cavity. One cannot imagine very well the segmental nerve supply jumping two sections, nor does it seem likely that the muscle fibres themselves have crossed over in the cone of condensation of mesoderm, from which they all come.

I am therefore at a loss as to the explanation of this case, unless it is caused by the spina bifida occulta of the cervical vertebrae, nor why the transplantation did not bring about the expected abduction of the eyes.

My thanks are due to Miss Mann for her kind advice.

\section{UNILATERAL FOLLICULAR CONJUNCTIVITIS DUE TO MOLLUSCUM CONTAGIOSUM*}

BY

\author{
JOHN A. MAGNUS \\ YOR K
}

THE rarity of this disease in this country justifies the publication of the following case :-

Mrs. F. E. W., aged 53 years. I saw the patient first on March 16, 1943, when she had an acute conjunctivitis and superficial keratitis of the right eye, which had developed after influenza. She was treated along the usual lines with guttae sodium sulphacetamide 30 per cent., boracic lotion and ung. merthiolate, 1 in 5,000, aolan injections and vitamin $\mathrm{C}$, but the condition did not clear up during the next two months.

Various investigations were carried out :-X-ray sinuses, N.A.D. ; Ear, nose and throat examination, N.A.D.; Mantoux, negative; Culture, sterile.

As they did not reveal the cause, the local treatment was changed, and guttae neoprotosil 10 per cent., and sol. hydrarg. oxycyanide, 1 in 5,000 , given. The conjunctiva was painted with the alum

\footnotetext{
* Received for publication January 3, 1944.
} 
stick and silver nitrate, 2 per cent. Sulphadiazine was given by, mouth.

Another month elapsed. The clinical picture showed a temporary improvement, and then relapsed, the conjunctiva showing the picture of a chronic inflammation with a few follicles.

In June, 1943, about three months after I first saw her, I noticed several umbilicated, small tumours (the size of a pinhead) on the right upper and lower lids. Two of them were encroaching upon the lid margins. I It was then that I first thought of molluscum contagiosu'm.

These tumours were removed for biopsy. Those at the lid margin were destroyed by electric cautery. A small piece of the conjunctiva showing follicular swelling was also excised.

During the next month the patient was treated with guttae sodium sulphacetamide, 30 per cent., and sodium sulphate solution, 12 per cent. Already, a fortnight after the removal of the small tumours, the conjunctiva had improved, and cleared up completely within a month.

The histological examination confirmed the clinical diagnosis.

\section{Microscopical Examination}

The conjunctiva shows diffuse infiltration with lymphocytes. This infiltration is confined to the sub-epithelial area (Figs. 1, 2, 3).

The fibrous tissue in this area is increased. The skin presents the typical picture of a molluscum contagiosum (Figs. 4, 5). This

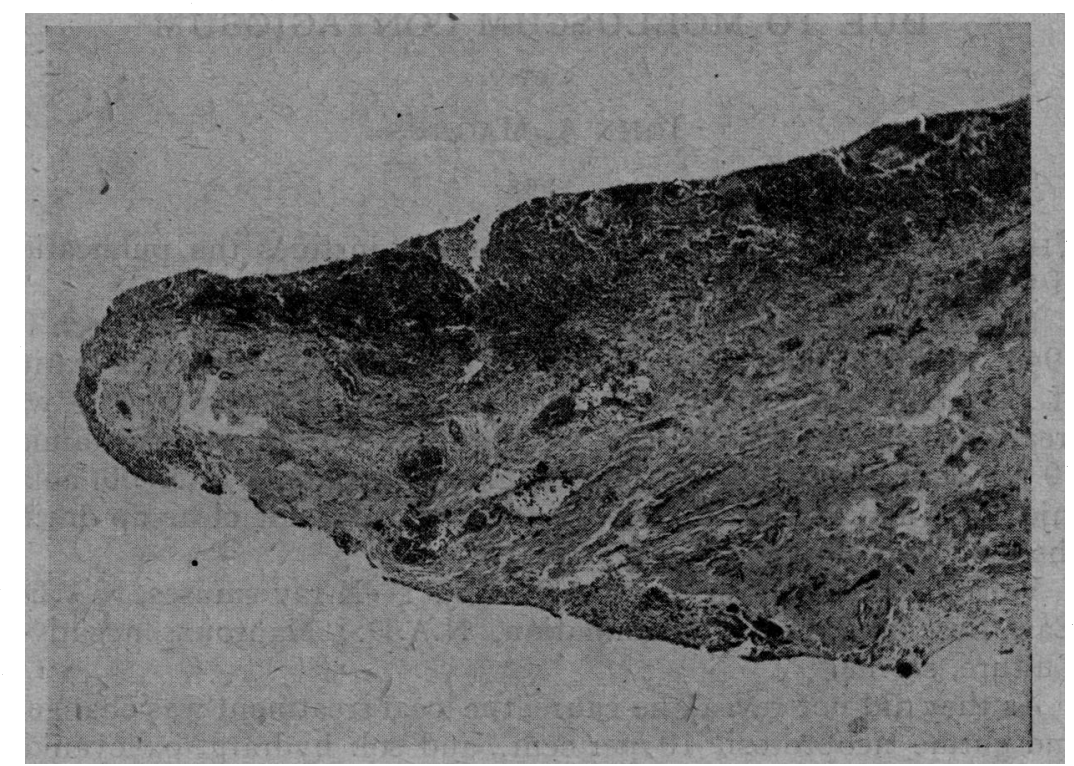

FIG. 1 . 
Unilateral Follicular Conjunctivitis Due to Molluscum Contagiosum

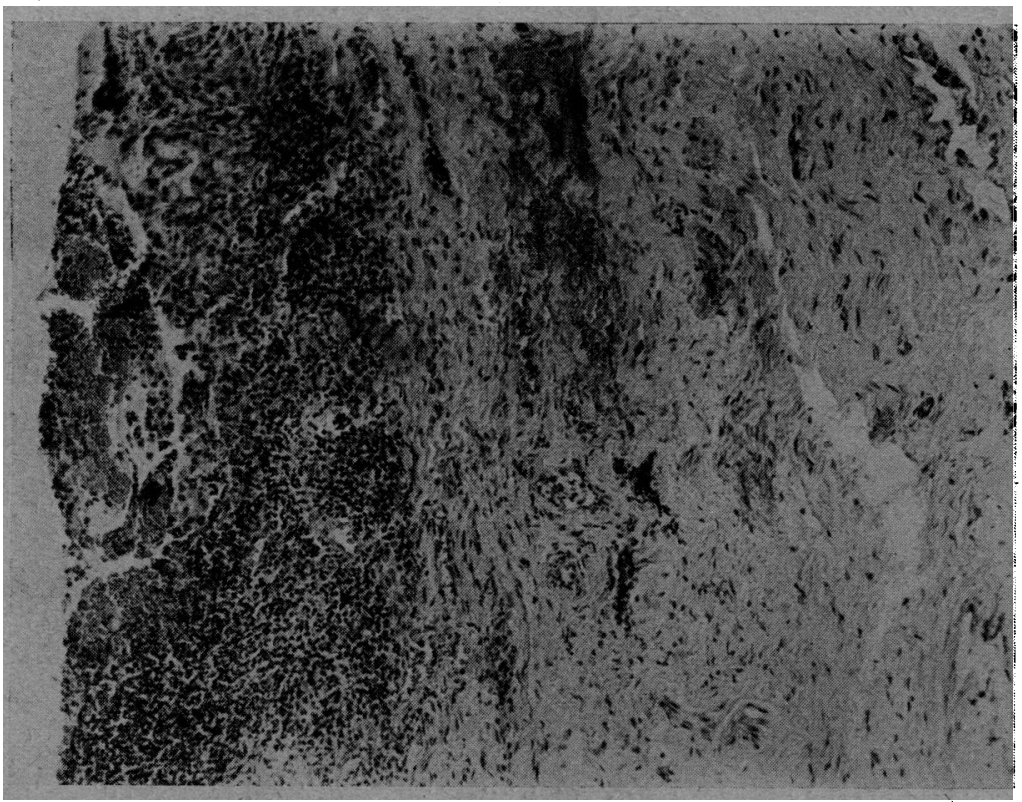

FIG. 2.

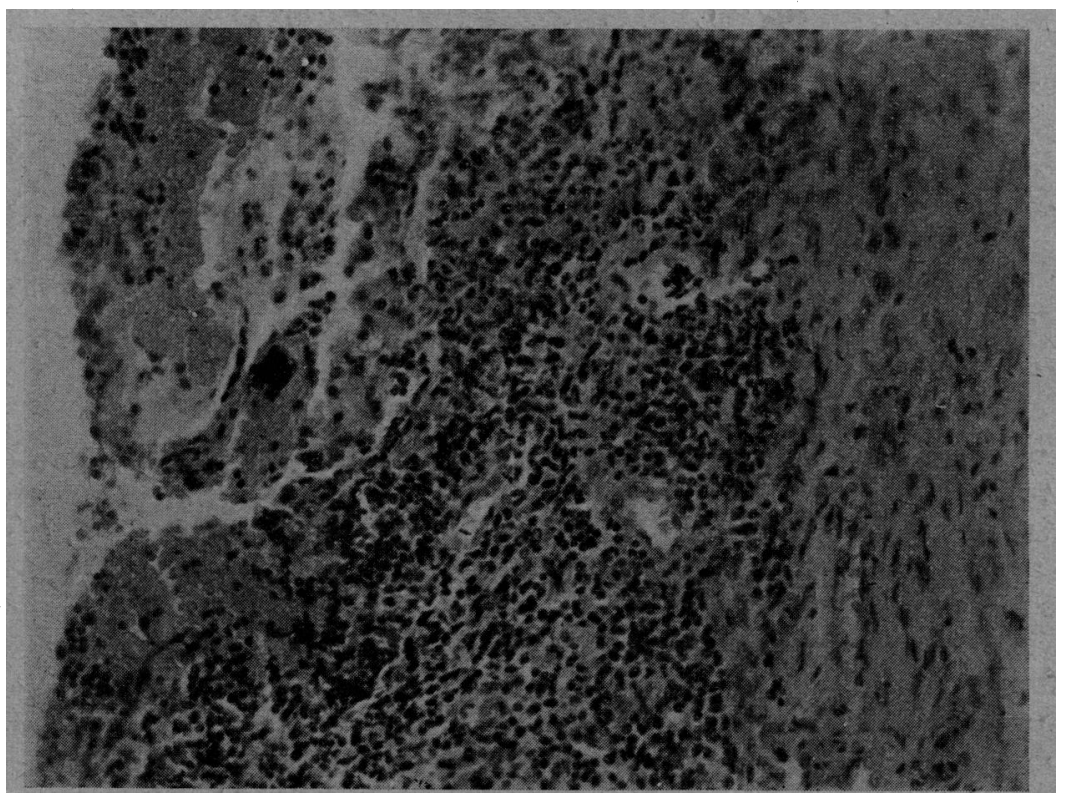

FIG. 3. 


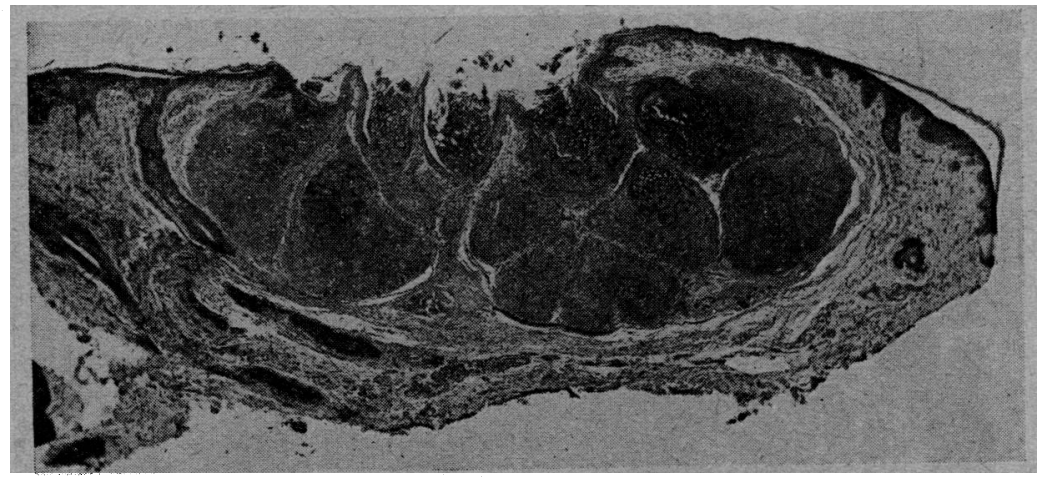

Fig. 4.

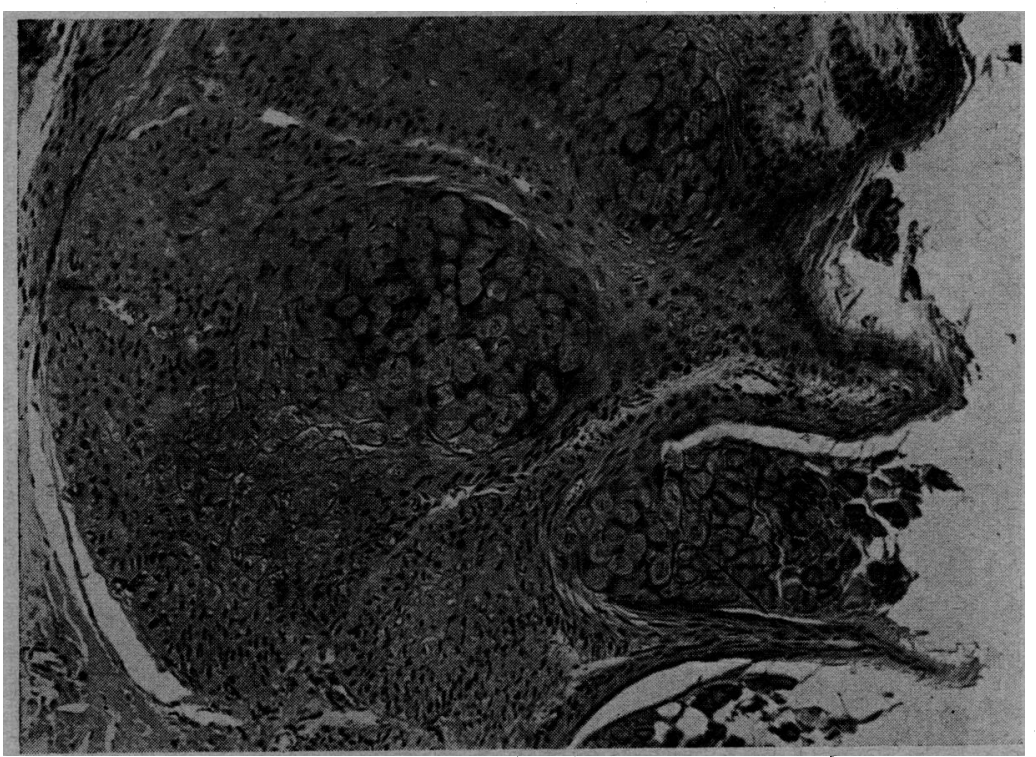

Fig. 5.

consists of an accumulation of epithelial cells which are separated from each other by thin strands of the sub-epithelial connective tissue. The epithelial cells are swollen and hypertrophic.

All stages of degeneration can be seen. In some the protoplasm is thickened and converted into a well-defined reticulated structure, with the nucleus pushed to one side, and in others the protoplasm stains deeply with eosin, showing the typical, fully-developed homogeneous molluscum bodies. One can recognize quite easily how the molluscum bodies are discharged on to the surface of the skin.

\section{REFERENCES}

HENKE and LUBARSCHE (1931).-- "Handbuch der speziellen pathologischen Anatomie und Histologie.'

DURE-ELDER (1939). - " Text-Book of Ophthalmology." 